\title{
JUAN DE ESPINAL: APUNTES BIOGRÁFICOS INÉDITOS Y UNA APORTACIÓN A SU CATÁLOGO
}

\author{
JUAN DE ESPINAL: UNPUBLISHED BIOGRAPHICAL \\ NOTES AND A CONTRIBUTION TO HIS CATALOGUE
}

\author{
José RodA PeÑa \\ Universidad de Sevilla. España \\ ORCID: 0000-0002-4141-1178 \\ roda@us.es
}

Damos a conocer unas notas documentales inéditas de la biografía del pintor Juan de Espinal (1714-1783), fechadas en 1760, así como un lienzo de la Virgen del Rosario, que puede atribuírsele con seguridad, conservado en una colección particular sevillana.

Palabras clave: Juan de Espinal; Virgen del Rosario; pintura sevillana; siglo XVIII; rococó.

We present some unpublished documentary notes from the biography of the painter Juan de Espinal (1714-1783), dated in 1760, as well as a canvas of the Virgin of the Rosary, which can be attributed to him with security, preserved in a particular Sevillian collection.

Keywords: Juan de Espinal; Virgin of the Rosary; Sevillian painting; $18^{\text {th }}$ century; Rococo.

Desde que Ceán Bermúdez lo conceptuara como "el pintor de más genio, de más instrucción artística y el más determinado en la práctica” de entre los artífices sevillanos de su generación ${ }^{1}$, la fortuna crítica de Juan de Espinal (1714-1783)

${ }^{1}$ Ceán Bermúdez, 1800: 32-33. El ilustre asturiano, que alardeaba de conocer bien a Juan de Espinal por haber sido alumno suyo en los comienzos de la Escuela de Nobles Artes, también deslizó en su apunte biográfico otras apreciaciones menos positivas, como su "floxedad natural"; en cierta medida, desde su particular óptica ilustrada, considera frustrados su "genio y talento" por "los malos principios que tuvo en la escuela de su maestro [Domingo Martínez]", que "impidieron que fuese el mejor pintor que había tenido Sevilla después de Murillo", aun sin dejar de reconocer que hizo gala de "un estilo original que no pudo haber tomado de ninguno de los que le precedieron en este siglo en la Andalucía". 
-con el importante hito de la única monografía que se le ha dedicado por el momento, en $1981^{2}$, hasta la historiografía más reciente ${ }^{3}$ - no ha hecho sino revalidar su papel prevalente en la pintura hispalense de la segunda mitad del siglo XVIII. Aprendiz, en primera instancia, de su padre, el modesto pintor Gregorio de Espinal (1684-1743) ${ }^{4}$, su verdadero discipulado se produjo junto a Domingo Martínez (1688-1749), de quien acabaría convirtiéndose en yerno al contraer matrimonio con su hija Juana en 1734, y heredando su nutrida colección de dibujos, modelos y estampas, a raíz de la muerte de aquel, en 1749. Dotado de una reconocida erudición y excelentes recursos técnicos, supo interpretar con elegancia y suma vitalidad el espíritu rococó de su tiempo, no siéndole ajenos la influencia del gusto cortesano y -ya en los últimos años de su trayectoria profesional- hasta los primeros planteamientos estéticos academicistas, plasmándose todo ello en una extensa producción pictórica, de corte muy personal desde el punto de vista morfológico y expresivo. Contó con el respaldo de una amplia y poderosa clientela -desde cardenales hasta el cabildo municipal, pasando por diversas órdenes religiosas, fábricas parroquiales y hermandades-, que le distinguió con su benéfica protección, accediendo a buena parte de los encargos más importantes de la época, tanto de pintura mural como de caballete, afrontando una temática mayoritariamente religiosa y de manera más puntual, profana, con algunos retratos y asuntos alegóricos y mitológicos. Asimismo, acometió tareas de tasación de obras artísticas, de dorado y estofado de mobiliario diverso e incluso la policromía de imágenes escultóricas, como la notable Mater Inviolata de Cayetano de Acosta que hoy preside la capilla del palacio arzobispal de Sevilla. Implicado desde su creación en la práctica docente de la Real Escuela de las Tres Nobles Artes, ejerció como director de su sección de Pintura desde 1775 hasta su fallecimiento en 1783, conociéndosele una estancia relativamente breve en Madrid a finales del año 1777.

Sirvan estas líneas para divulgar, en primer lugar, unas noticias biográficas inéditas sobre Juan de Espinal y su entorno familiar que hemos localizado en un par de documentos, ambos fechados en 1760 y conservados en la sección de

Sobre el período de aprendizaje de Ceán con Espinal y el ambivalente juicio crítico que le merecían la obra y estilo de este último a la hora de publicar su Diccionario, véase Cabezas García, 2015a: 130-133, 148-154.

${ }^{2}$ Perales Piqueres, 1981.

${ }^{3}$ Reseñaremos, entre las últimas aportaciones registradas a propósito de la personalidad y producción artística de Juan de Espinal, los trabajos de Valdivieso, 2003: 553570. Quiles García/Cano Rivero, 2006: 180-183. Fernández López, 2007: 186-189. Cabezas García, 2009-2010: 201-208; 2015a: 327-341, 356-361; 2015b: 11-32. Rojas-Marcos González, 2018: 457-463. Valdivieso, 2018: 319-332.

${ }^{4}$ Las fechas correctas del nacimiento y muerte de Gregorio de Espinal han sido recientemente publicadas por Cañizares Japón, 2017: 311. 
protocolos notariales del Archivo Histórico Provincial de Sevilla. En el primero de ellos, se nos viene a informar de la existencia de una capellanía fundada en la parroquia de San Gil por Antón Martín Garrido, en una de cuyas cláusulas de erección se expresaba que, a falta de un patrono, podrían designarlo tres beneficiados propios de dicho templo, en unión de otros tantos vecinos de aquella misma collación, "con la circunstancia que huviese de ser la persona que así se nombrase lega y honrada". Tal eventualidad, efectivamente, llegaría a darse, por lo que los presbíteros Juan Gutiérrez, Manuel Vallejo y Miguel Moreno, junto a los feligreses Andrés Escribano, Alonso Valentín Pantoja y Pedro Liñán, procedieron al nombramiento, ante el notario público apostólico Francisco Antonio Morales de Soria, del pintor Domingo Martínez como patrono perpetuo de la citada capellanía, revelándosenos el dato, desconocido hasta ahora, de que el afamado artífice había sido mayordomo de la fábrica parroquial de San Gil. La escritura fundacional de la capellanía facultaba al patrono el poder nombrar a su sucesor, "para después de los días de su vida", y así lo hizo Domingo Martínez con su yerno Juan de Espinal el 18 de junio de 1745, ante el escribano público Juan José de Ojeda y Martel. Pasados casi quince años desde entonces, el 14 de febrero de 1760, Juan de Espinal hizo lo propio en la persona de Domingo de Espinal, "su hijo lexítimo y de D. ${ }^{a}$ Juana Martínez su muxer, por ser persona ávil y suficiente y en quien concurren las partes y calidades prevenidas por dicha fundazión, y con las mismas facultades de poder el suso dicho nombrar patrono de dicha capellanía para después de su vida, nombrar capellanes que la sirvan todas las veses que se ofreziere a quien sea su voluntad, guardando siempre en los tales nombramientos de capellanes el horden y forma según previene dicha fundazión" . Al respecto de lo que llevamos enunciado, deberá recordarse que el hecho de ser patrono de una capellanía, además de las obligaciones que conllevaba su desempeño - vigilar el cumplimiento de las condiciones estipuladas en su fundación, proponer el nombramiento de capellán, comprobar la observancia de las cargas espirituales, asistir a la visita de la capellanía-, suponía un claro signo de prestigio social ${ }^{6}$. Este instrumento de distinción fue sin duda utilizado por Domingo Martínez para prorrogarlo en el seno de su familia, nombrando a su hijo político Juan de Espinal como sucesor suyo en el patronato perpetuo de aquella capellanía fundada en la parroquia hispalense de San Gil, así como este último

${ }^{5}$ Archivo Histórico Provincial de Sevilla (AHPSe), sección Protocolos Notariales, legajo 9556, oficio 15, libro único de 1760, f. 86.

${ }^{6}$ Castro Pérez/Calvo Cruz/Granado Suárez, 2007: 340-341. 
usó de la misma prerrogativa con su hijo Domingo de Espinal Martínez (1743$1800)^{7}$, de quien se conoce su doble condición de sacerdote y pintor $^{8}$.

El segundo de los documentos que presentamos está fechado el 24 de marzo de 1760, tratándose de una escritura pública por la que Juan de Espinal, "Artífize del arte de la Pintura" y vecino de la collación de San Lorenzo, como marido de Juana Martínez, "poseedora del vínculo que fundó D. Domingo Martínez mi suegro", otorgaba en arrendamiento a José de Posaela una casa corral de vecinos, perteneciente al citado mayorazgo, localizada en el barrio de la Macarena "a el sitio de la Rezolana", para que la gozara durante un tiempo de tres años, debiendo abonarle una renta mensual de 89 reales. Espinal hace constar que dicho inmueble tenía necesidad de algunos reparos, quedando obligado a que en cuanto el inquilino le diera aviso, habría de ejecutarlos sin demora alguna. A la condición anterior se añadía el hecho de que, ya que estaba en trámite la venta de dicha casa, sería forzoso incluir en su enajenación la permanencia de este alquiler, para no producir ningún perjuicio al ocupante ${ }^{9}$. Estamos, pues, ante un testimonio indicativo de la que se convirtió en una de las fuentes habituales de ingreso para los artistas sevillanos de la Edad Moderna, como fue la gestión de sus propiedades inmobiliarias para con ello obtener unos ingresos económicos suplementarios a los provenientes de su quehacer profesional.

Todos los estudiosos de Espinal coinciden en que a comienzos de la década de 1760 es cuando su obra alcanza una plena madurez artística. Sin que podamos precisar la fecha de su ejecución, damos a conocer la existencia en una colección particular sevillana de un óleo sobre lienzo de pequeño formato $(40 \times 31 \mathrm{~cm})$, que nos parece merecedor de engrosar el catálogo de Juan de Espinal, como una obra de segura atribución, dada la carencia de firma y de respaldo documental que certifique fehacientemente su autoría. Representa esta pintura a una Virgen del

${ }^{7}$ Debo el conocimiento de las fechas de nacimiento (26 de octubre de 1743 ) y sepultura ( 8 de octubre de 1800) de Domingo de Espinal Martínez a la generosidad de mi buen amigo Ramón Cañizares Japón.

${ }^{8}$ En el acta de la junta celebrada por la Real Escuela de las Tres Nobles Artes de Sevilla el 6 de enero de 1801, su secretario Cabral Bejarano hace constar entre los fallecidos durante la epidemia de 1800 a "Don Domingo Espinal, presbítero, que pintó las copias de los cuadros de la Caridad que están en San Jerónimo de Buenavista". Muro Orejón, 1961: 24. Formó parte del equipo de ayudantes que auxiliaron a su padre, Juan de Espinal, en la decoración pictórica del techo de la escalera del palacio arzobispal sevillano. Falcón Márquez, 1992: 385-392. Consta que Domingo de Espinal, desde el 6 de agosto de 1783, pocos meses antes del fallecimiento de su padre, se obligó a pagar una renta mensual de 20 reales por vivir en una casa que la Hermandad Sacramental de San Lorenzo -a la que estuvo tan vinculada toda su familia- poseía en la actual calle Guadalquivir. Cañizares Japón, 2011: 96-97.

9 AHPSe, sección Protocolos Notariales, legajo 9556, oficio 15, libro único de 1760, f. 160 . 
Rosario y, tras haber sido restaurada por Enrique Gutiérrez Carrasquilla durante los meses de junio y julio de 2014, presenta todas las características de estilo que avalan esta asignación que proponemos (Figura 1).

Aparece la Virgen, en compañía del Niño Jesús, entronizada en un ámbito celestial, sentada sobre un cúmulo de nubes del que emergen caprichosamente unos angelitos niños de dinámicas posturas y miembros escorzados, los tres de nuestra izquierda dialogando entre sí (Figura 2), al tiempo que sendas cabezas aladas de querubes se sitúan justo a las plantas de María. Otros estratos nubosos, a los que asoman nuevas testas de serafines, ciñen en círculo la evanescente atmósfera que respalda la mitad superior de la composición, que se tiñe de tonalidades anaranjadas propias de la luz crepuscular que baña la escena desde el ángulo superior izquierdo, provocando tenues sombras que otorgan plasticidad a las anatomías de los protagonistas y a sus prendas textiles, hasta dejar sumido en la penumbra todo el sector inferior derecho del cuadro.

La figura sedente de la Virgen, vestida con túnica rosa y un amplio manto azul, muestra una silueta nítidamente romboidal. Sobre su cabeza, cuyos cabellos apenas están velados por una toca marfileña, luce una corona de imperiales, titilando alrededor suya las doce estrellas que refulgen sobre el cielo iluminado por los áureos resplandores que circundan el busto mariano. María sujeta al pequeño infante en su regazo, portando el cetro de realeza en su mano izquierda. Frente a la sensación de quietud y solemnidad que desprende la efigie materna, el Niño, ciñendo asimismo una corona imperial, ha sido captado por los pinceles de Espinal en pleno movimiento, propio de la inquieta espontaneidad de su corta edad, que no le permite quedarse tranquilamente sentado sobre el cojín dorado con borlones que reposa sobre la pierna izquierda de su madre. Tanto ella como su hijo, con expresiones apacibles, fijan la mirada en el espectador, reclamando su atención sobre el objeto que sostiene Jesús entre sus manos, y que no es otro sino el rosario que brinda su advocación a esta Virgen de rostro ovalado y rasgos perfectamente reconocibles en la producción autógrafa de Espinal, como también lo son, desde el punto de vista técnico, su dibujo suelto, la pincelada restregada y de gran ligereza de trazo, el refinado primor de la paleta cromática, llena de exquisitos matices, y lo acertado del tratamiento lumínico (Figura 3).

Puede decirse que en esta pintura perviven reminiscencias de modelos murillescos rebosantes de delicadeza e intimismo, como el representado por la Virgen del Rosario de la Dulwich Picture Gallery de Londres (hacia 1675-1682); evocaciones tamizadas a través de la mirada de Domingo Martínez, como la que nos brinda en el homónimo lienzo del Museo de Bellas Artes de Sevilla (hacia 1745), a las que su discípulo Juan de Espinal supo añadir intensos efluvios procedentes de la tendencia rococó y matices personales en la interpretación iconográfica del tema tratado.

Fecha de recepción: 19 de septiembre de 2019

Fecha de aceptación: 23 de febrero de 2020 


\section{BIBLIOGRAFÍA}

Cabezas García, Álvaro (2000-2010): “Un caso de peritaje artístico en el siglo XVIII: Juan de Espinal y Juan Ruiz Soriano en el Hospital de la Caridad de Sevilla". En: Atrio, 15-16, pp. 201-208.

(2015a): Teoría del gusto y práctica de la pintura en Sevilla (1749-1835). Sevilla: Ayuntamiento de Sevilla-Instituto de la Cultura y las Artes de Sevilla (ICAS).

(2015b): "Venus y Vulcano de Juan de Espinal: precisiones sobre su iconografía y medio artístico". En: Revista de Humanidades, 26, pp. 11-32.

Cañizares Japón, Ramón (2011): "Noticias de la Hermandad Sacramental de San Lorenzo en el siglo XVIII". En: Roda Peña, José (Dir.): XII Simposio sobre Hermandades de Sevilla y su provincia. Sevilla: Fundación Cruzcampo, pp. 73-104.

(2017): San Lorenzo. Un barrio en la Historia de Sevilla. Sevilla: el autor.

Castro Pérez, Candelaria/Calvo Cruz, Mercedes/Granado Suárez, Sonia (2007): "Las capellanías en los siglos XVII-XVIII a través del estudio de su escritura de fundación". En: Anuario de Historia de la Iglesia, 16, pp. 335-347.

Ceán Bermúdez, Juan Agustín (1800): Diccionario histórico de los más ilustres profesores de las Bellas Artes en España. Madrid: Imprenta de la Viuda de Ibarra, vol. II.

Falcón Márquez, Teodoro (1992): "Documentación de las pinturas de Juan de Espinal en la escalera del Palacio Arzobispal de Sevilla”. En: Cuadernos de Arte de la Universidad de Granada, 23, pp. 385-392.

Fernández López, José (2007): "Domingo Martínez y Juan de Espinal: nuevas atribuciones de pinturas de la escuela sevillana del siglo XVIII". En: Laboratorio de Arte, 20, pp. 183-192.

Muro Orejón, Antonio (1961): Apuntes para la historia de la Academia de Bellas Artes de Sevilla. Sevilla: Imprenta Provincial.

Perales Piqueres, Rosa María (1981): Juan de Espinal. Sevilla: Diputación Provincial de Sevilla.

Quiles García, Fernando/Cano Rivero, Ignacio (2006): Bernardo Lorente Germán y la pintura sevillana de su tiempo (1680-1759). Madrid: Fernando Villaverde.

Rojas-Marcos González, Jesús (2018): "Nuevas obras de los pintores Domingo Martínez y Juan de Espinal". En: Cañestro Donoso, Alejandro (coord.): Scripta Artium in Honorem. Prof. José Manuel Cruz Valdovinos. Alicante: Universidad de Alicante, pp. 452-469.

Valdivieso, Enrique (2003): Pintura Barroca Sevillana. Sevilla: Guadalquivir Ediciones. 
(2018): La escuela de Murillo. Aportaciones al conocimiento de sus discípulos y seguidores. Sevilla: Editorial Universidad de Sevilla, Ayuntamiento de Sevilla-Instituto de la Cultura y las Artes de Sevilla (ICAS). 


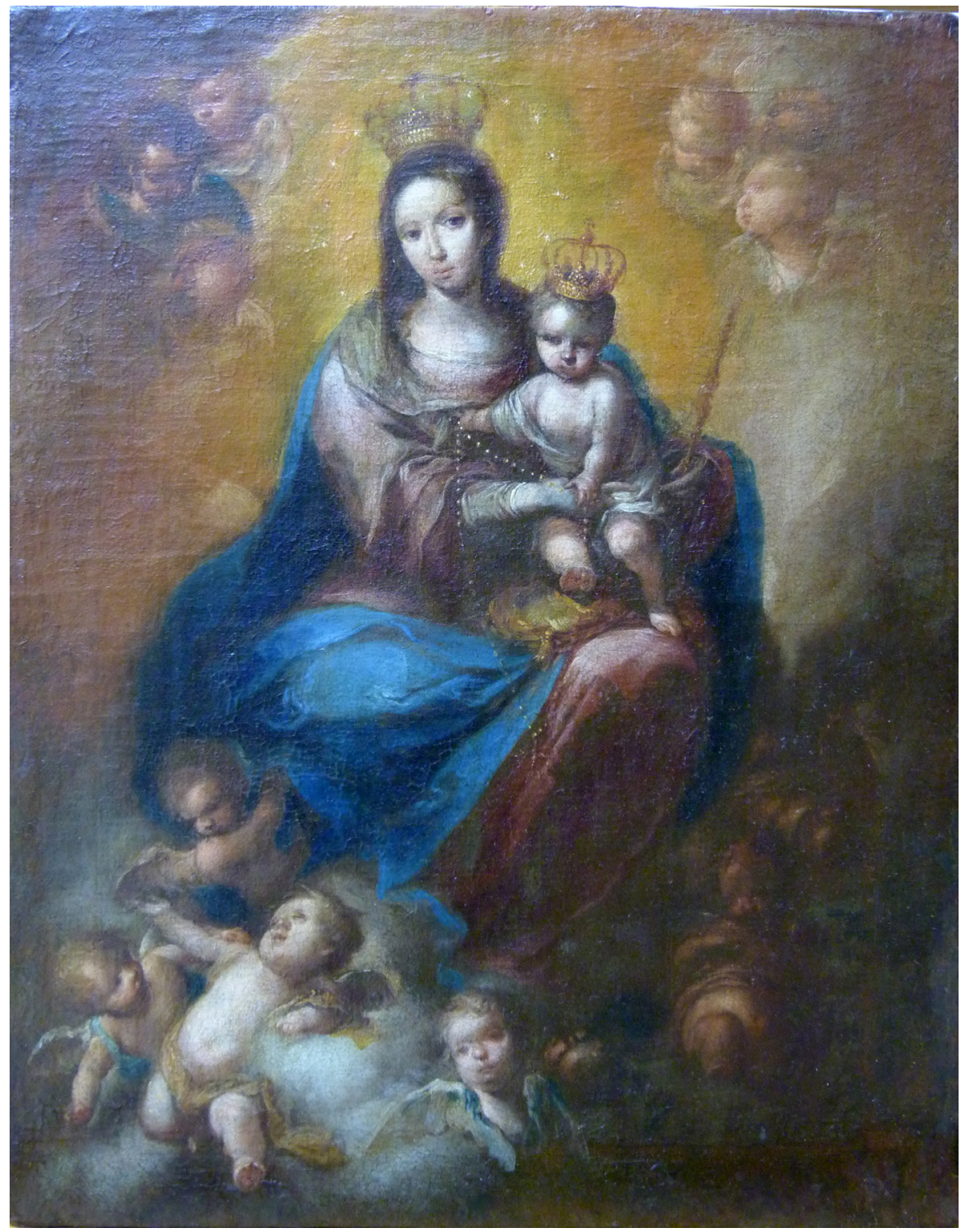

Figura 1. Juan de Espinal, Virgen del Rosario, colección particular, Sevilla. Foto: Enrique Gutiérrez Carrasquilla. 


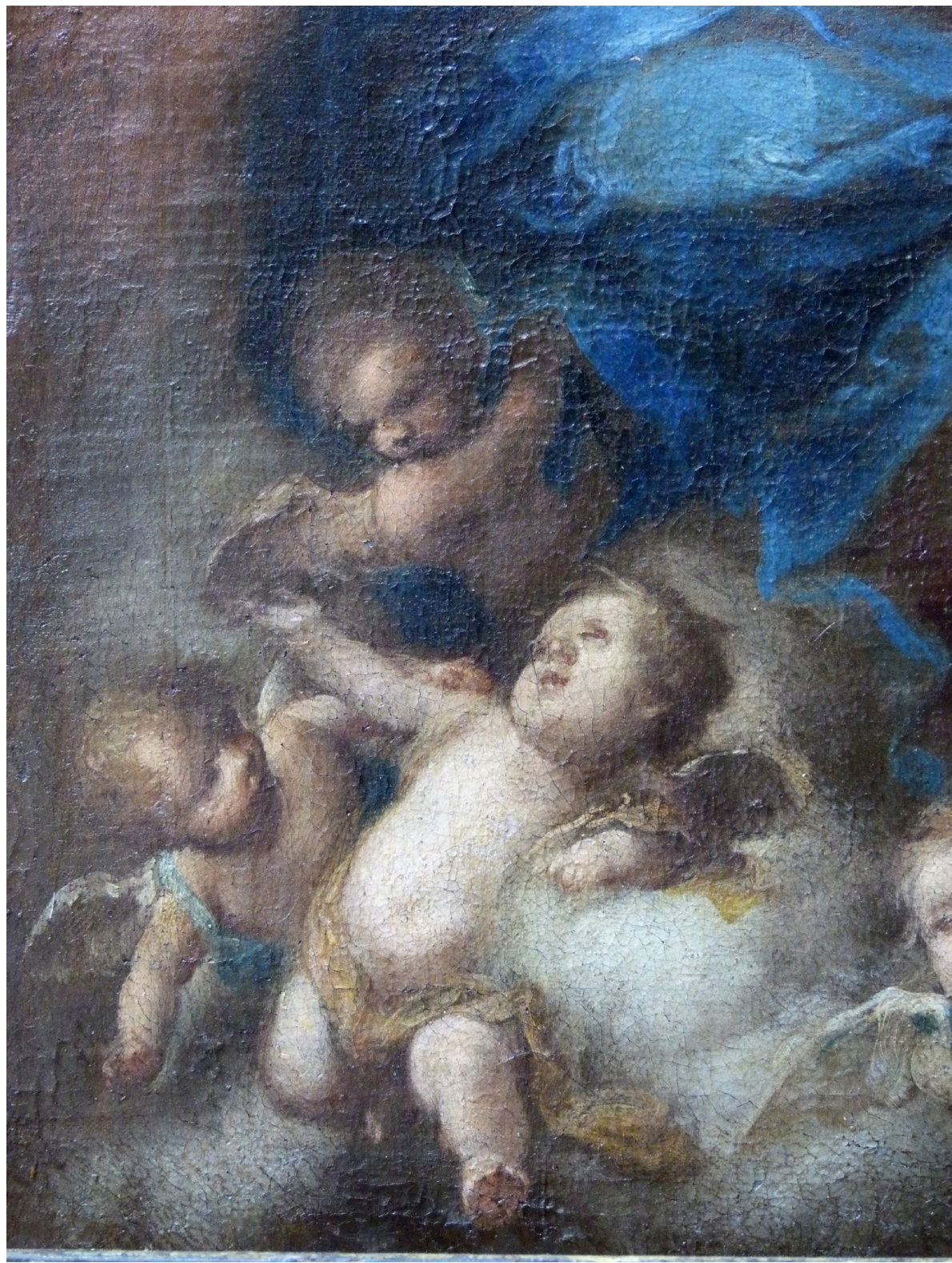

Figura 2. Juan de Espinal, Virgen del Rosario (detalle de los ángeles niños), colección particular, Sevilla. Foto: Enrique Gutiérrez Carrasquilla. 


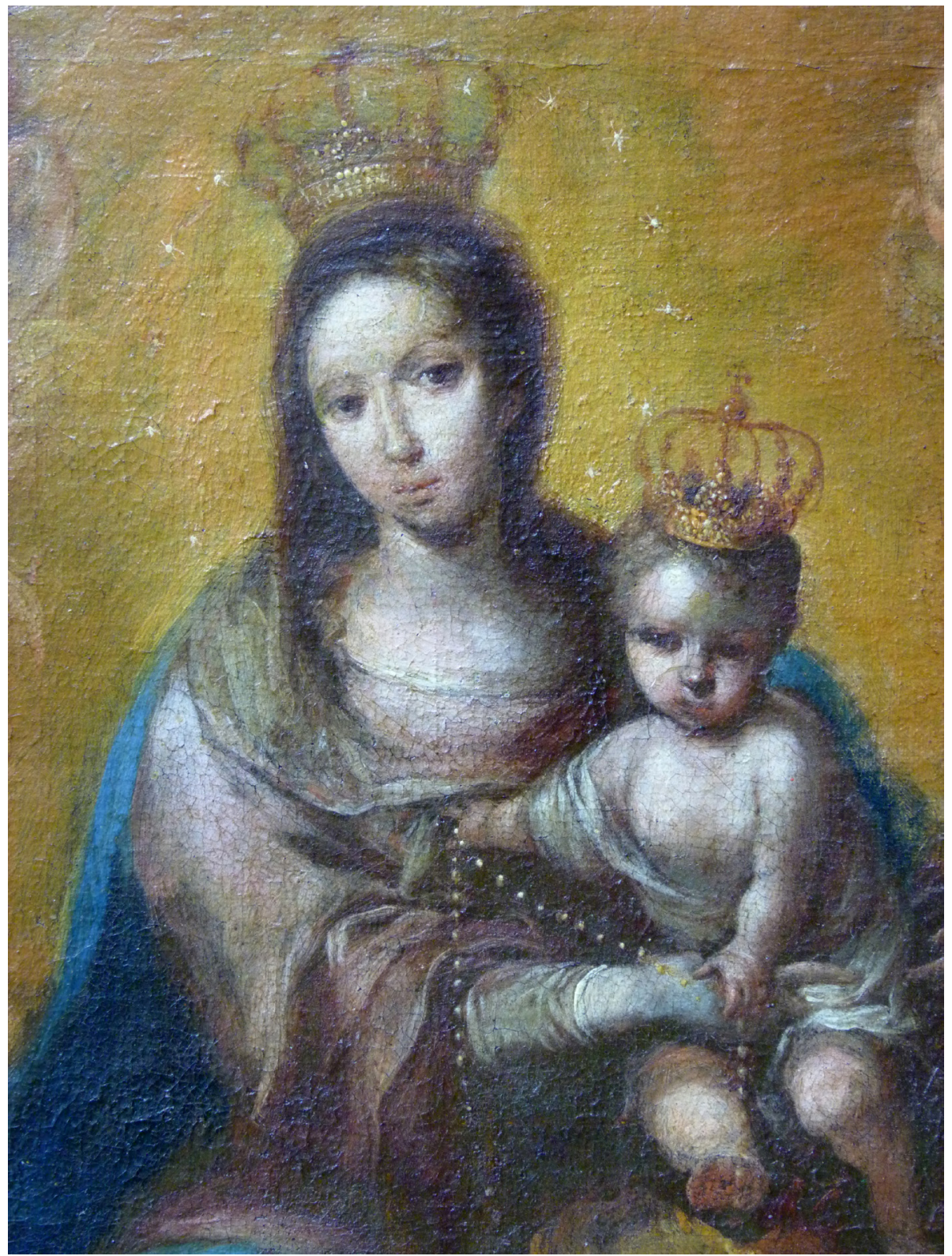

Figura 3. Juan de Espinal, Virgen del Rosario (detalle de la Virgen con el Niño Jesús), colección particular, Sevilla. Foto: Enrique Gutiérrez Carrasquilla. 